\title{
AN HISTORIC SPOT FOR STUDENTS OF GENETICS
}

\author{
J. C. ThEODORE UPHOF \\ Orlando, Florida.
}

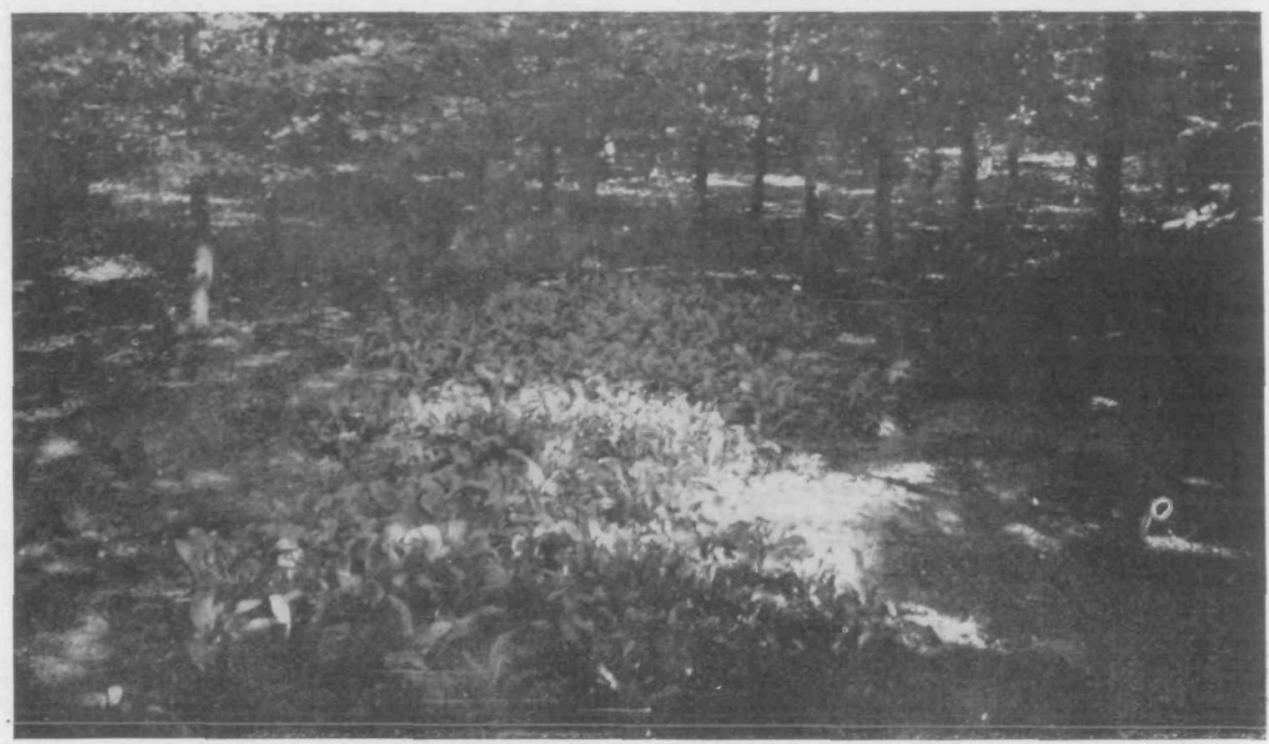

\section{THE PRIMROSES OF SPANDERSWOUD}

Figure 5. About $188_{5}$ this was a neglected potato field, and here Hugo de Vries discovered the mutant form of the Evening Primrose, on which he based his theory of evolution by mutation. Since that time the forest of beech and spruce trees has grown up and nearly wiped out the Oenotheras. In I92I only a few were left and the shade was so dense that photographs were impossible. The pictures shown here were made in 1908, and as far as known, are the only ones published of this interesting place.

$\mathrm{N}$ OT far from Amsterdam, a road branches off to the westward from the highway between Bussum and Hilversum. It leads through sandy fields and pine forests to the region of the lakes of Ankeveen. Passing through the old Dutch private estates of Swanenburg and Boekenstein, surrounded with beautiful gardens and woods, the traveller reaches Spanderswoud, one of the largest estates in that part of the country. It was here in I886 that Hugo de Vries found the first mutating Oenotheras, which were so important in the upbuilding of his theory of mutation.
According to de Vries, the Oenotheras were found in a neglected potato field, where they grew abundantly. The writer visited this place repeatedly between 1904 and 1908 and found it largely covered with a mixed forest of beech (Fagus sylvatica) and spruce (Picea excelsa). The forest was about fifteen years old, but some patches of Oenothera lamarkiana were still to be found in the open places.

Among the several thousand plants of the mother species there were but few of the forms to which de Vries gave the name $O$. nanella. In the autumn, when only the leaf rosetts were 


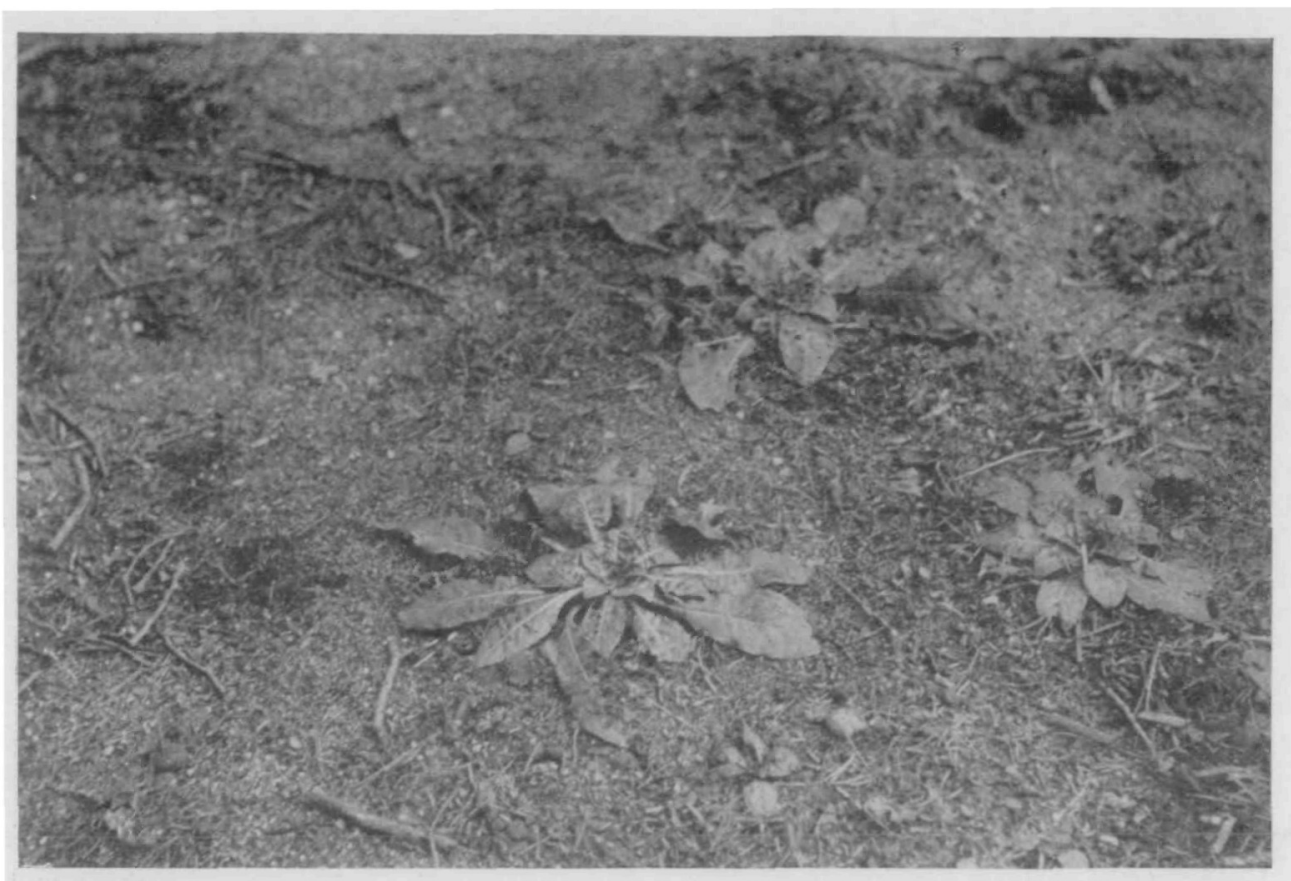

\section{A MUTANT ON ITS NATIVE hEATH}

Figure 6. Three rosettes of the normal $O$. lamarkiana are shown, and in the right foreground is one of the mutants, a tiny plant of the type called $O$. nanclla by de Vries.

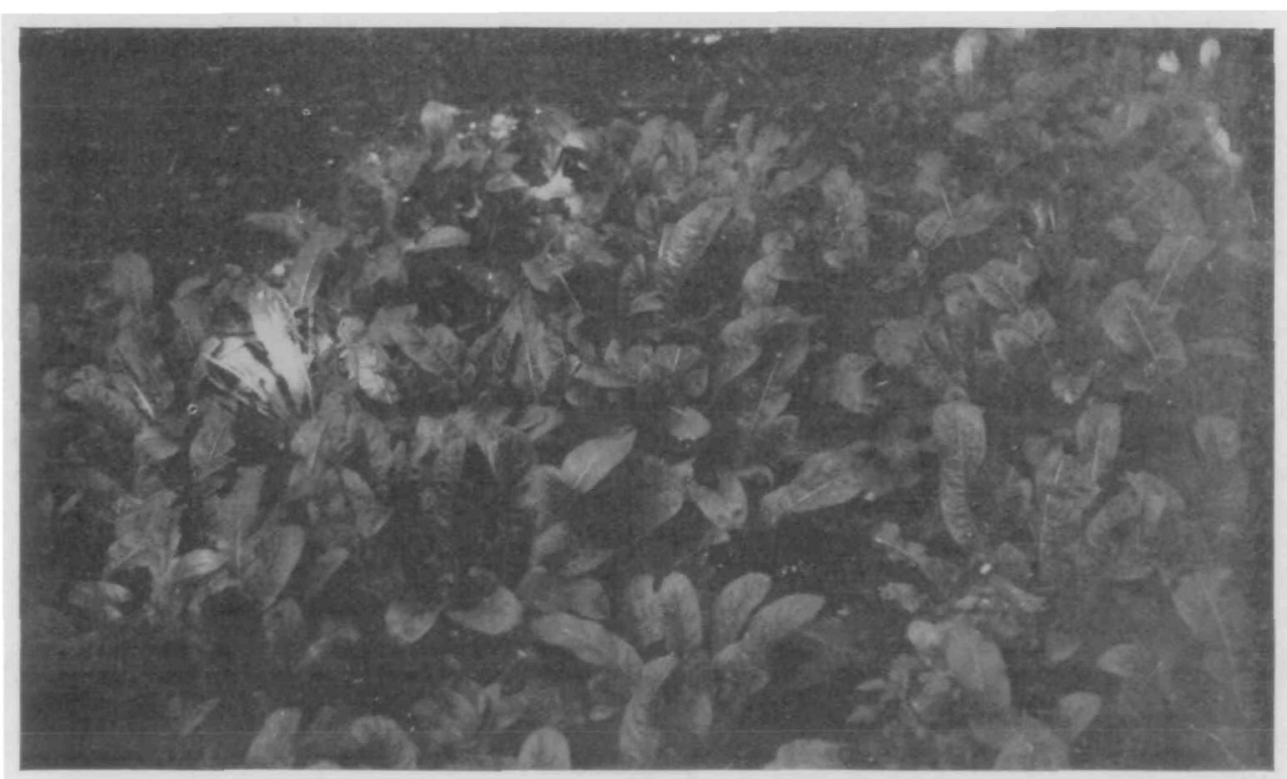

THE FOUNDATION OF A GREAT THEORY

Figure 7. Even should de Vries' theory of evolution be finally discarded by students of biology, there could be no doubt of the value of his researches. They gave the impetus so much needed to make the study of evolution an experimental rather than theoretical science. Great strides have been made in our understanding of heredity and evolution, until now we have reached the paradoxical position of realizing how little we really know about this most interesting of subjects,--the scientific study of life itself. 
to be found, I observed sporadic individuals of the minus mutant, so different from the typical lamarkiana in leaf form. Figure 6 shows in nature rosettes of Oenthera lamarkiana, between which a mutation, rianella, is growing. This plant was removed to my garden near Amsterdam, where it flourished and produced seed. Its offspring were. all dwarfs, which emphasized de Vries' observation ' that nanella is one of the most constant of the mutants.

Between I9Io and I92I the beech and spruce trees increased considerably in size, whereas the Oenotheras decreased in number so greatly that it appears that they will become extinct in a few years. It was practically im'possible to get photographs of the few remaining specimens, therefore the accompanying photographs are those of the plants found in 1908 .

As far as I am aware, no photo- graphs have ever been published of this historical and remarkable place, the starting point for investigations which have figured so conspicuously in modern discussions of the origin of new forms of living organisms. To students of genetics it may be especially interesting to have these pictures reproduced during the month of February, when Hugo de Vries, the founder of Experimental Evolution, reaches the seventy-fifth anniversary of his birth.

No doubt all geneticists agree that Dr. de Vries' theory and researches of evolution have thrown a powerful beam on the phenomena of the origin of species. His brilliant discoveries and his revival of Mendel's researches have stimulated scientific investigation and laid the foundation for much successful work in plant and animal breeding.

\section{Hybrids and Mutations of Campanula}

I VTERESTING results are reported by Lathouwers for experiments with Gampanula medium. Hybrids between rose colored and white flowered varieties gave in the first generation dark violet-colored flowers, and in the second generation five classes of flower color are reported, white, rose, dark violet, violet, and lilac in various proportions. These results were difficult to understand, but were finally adjusted to Mendelian theories by assuming four genetic factors. A basic color factor, and a "revealer" must both be present to produce color. A third factor is supposed to. determine alkalinity, and to be responsible for violet or dark violet -instead of rose or lilac. The fourth factor is assumed to be an intensifier, changing violet into dark violet or rose into lilac.

When the third factor is absent a form called monantha appeared, considered to be a true mutation. It is characterized by a large solitary flower, with no lateral flowers or branches. Suddenly in a pedigree culture after two generations of self-fertilization the mutation was represented by eighteen individuals, while seventy-five other plants retained the normal form. This same mutant form appeared in later generations, and came nearly true to seed. Crosses were also made with this and other floral abnormalities.'

ISee Lathouwers, M. V. Researches Experimentales sur L'Heredité chez Campanula medium $L$. L'Academie Royale de Belgique. No. 1283.1922. 